\title{
A Case of Using Hominis Placenta and Soyeom Mixed Pharmacopuncture to Remove Melanocytic Nevus
}

\author{
Hyung-Sik Seo* \\ *Department of Ophthalmology, Otolaryngology and Dermatology, School of Korean Medicine, Pusan National University
}

\section{Key Words}

placenta, soyeom, pharmacopuncture, melanocytic nevus, pigmented nevus, alternative and complementary medicine

\footnotetext{
Abstract

Objective: It has been attempted to find out that Homine Placents and Soyeom mixed Pharmacopuncture (HSP) procedure is effective for the removal of melanocytic nevus of considerable size which cannot be applied to general acupuncture.

Methods: Hominis placenta $(0.5 \mathrm{ml})$ and Soyeom $(0.5 \mathrm{ml})$ mixed pharmacopuncture $(1.0 \mathrm{ml})$ was subcutaneously injected in several places of melanocytic nevus. The treatment was performed about 20 times, once a week. Layer analysis of pigmentation was carried out using ECOSKIN.
}

Results: One year after the HSP procedure, the pigmentation of the melanocytic nevus was slightly reduced and completely removed after 2 years of procedure.

Conclusion: The HSP could be effective for removing hyperpigmentation in the melanocytic nevus.

Received: Oct 03, 2017 Reviewed: Mar 14, 2018 Accepted: Mar 16, 2018

(c) This is an Open-Access article distributed under the terms of the Creative Common Attribution Non-Commercial License (http://creativecommons.org/licenses/by-nc/4.0/) which permits unrestricted noncommercial use, distribution, and reproduction in any medium, provided the original work is properly cited.

(2) This paper meets the requirements of KS X ISO 9706, ISO 9706-1994 and ANSI/NISO Z39.48-1992 (Permanence of Paper).

\section{Introduction}

Melanocytic nevus corresponding to hyperpigmentation disease, is a common, largely benign, skin condition resulting from a proliferation of pigmented nevus cells. Melanocytic nevus does not usually require treatment unless malignancy is suspected, and in most circumstances removal is performed solely for cosmetic reasons [1]. The major treatment for removal of melanocytic nevus is surgical excision, laser therapy, electrocautery, chemical peel, cryotherapy, etc. [1,2].

The causes of hyperpigmentation are not clearly known, but the occurrence of deficiency fire (虛火) due to lack of kidney yin (腎陰), i.e., yin deficiency with effulgent fire (陰虛火旺) is suggested as a cause [3]. Inflammation related cytokines can stimulate melanocytes and induce pigmentation of the skin $[4,5]$. The Hominis placenta pharmacopuncture is an effective drug used in the pathogenesis of fire excess from Yin deficiency [6], and has been reported to inhibit pigmentation [7]. The Soyeom pharmacopuncture have the effect of inhibiting inflammatory cytokines [8].

Therefore, it is suggested that Hominis placenta and Soyeom mixed pharmacopuncture (HSP) is synergistic for improving pigmentation, so that they can effectively treat melanocytic nevus. They are applied clinically and present that it can be effective.

\section{Case Report}

A 58 - year - old woman presented with facial pigmentation and was diagnosed with melanocytic nevus (Fig. 1.). She experienced laser treatment once in the 
past, and recurred after disappearance. The recurrence time was not clear, and the current history and family history of recurrence were not specific. Biopsies were not performed, and layer analysis of pigmentation was carried out using ECOSKIN (Cuvitz Inc.) (Fig. 2.).

Hominis placenta $(0.5 \mathrm{ml})$ and Soyeom $(0.5 \mathrm{ml})$ mixed pharmacopuncture $(1.0 \mathrm{ml})$ was subcutaneously injected in several places of melanocytic nevus. The treatment was performed 21 times, once a week (2014.06.09 - 2014.10.27). One year later, the procedure was repeated twice (2015.06.22, 06.24) (Fig. 3.). Layer analysis of pigmentation was carried out using ECOSKIN (Fig. 4.). One year later (2016.10.10), when she went back to the outpatient clinic, the nevus had disappeared (Fig. 5.). No other treatment was received during the course. The final ECOSKIN test was not performed because the nevus was lost.

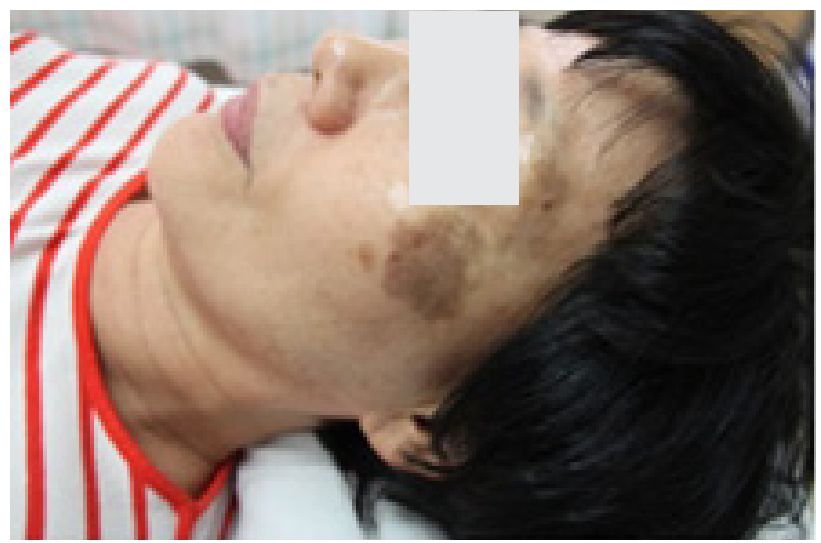

Figure 1 June 9, 2014 Appearance at the time of admission

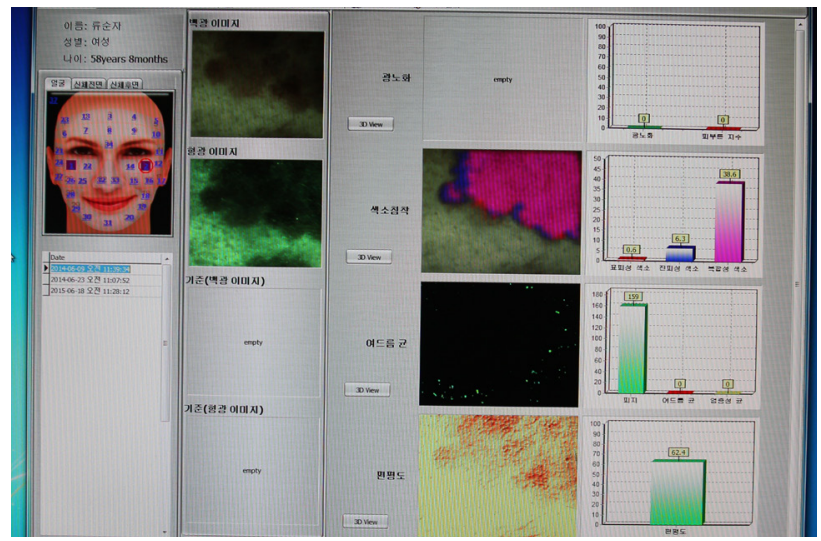

Figure 2 ECOSKIN test, June 9, 2014 Appearance at the time of admission

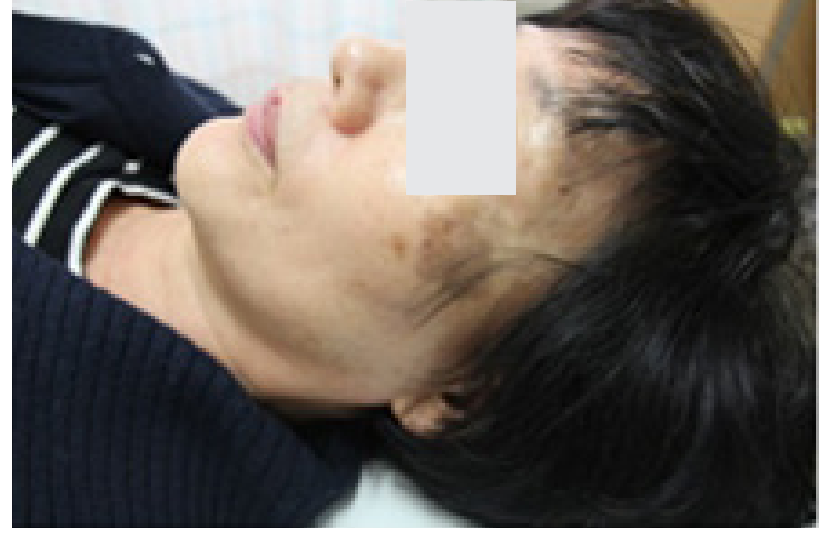

Figure 3 June 22, 2015 Appearance at the time of admission

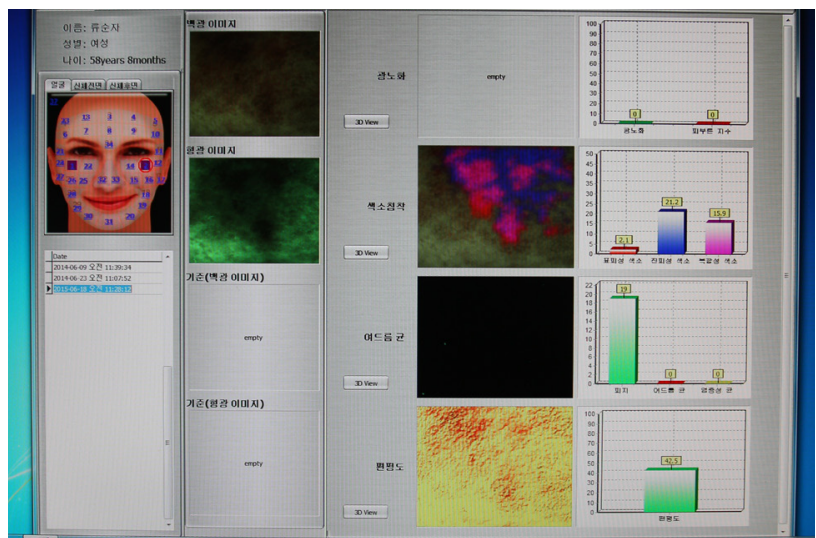

Figure 4 ECOSKIN test, June 22, 2015 Appearance at the time of admission

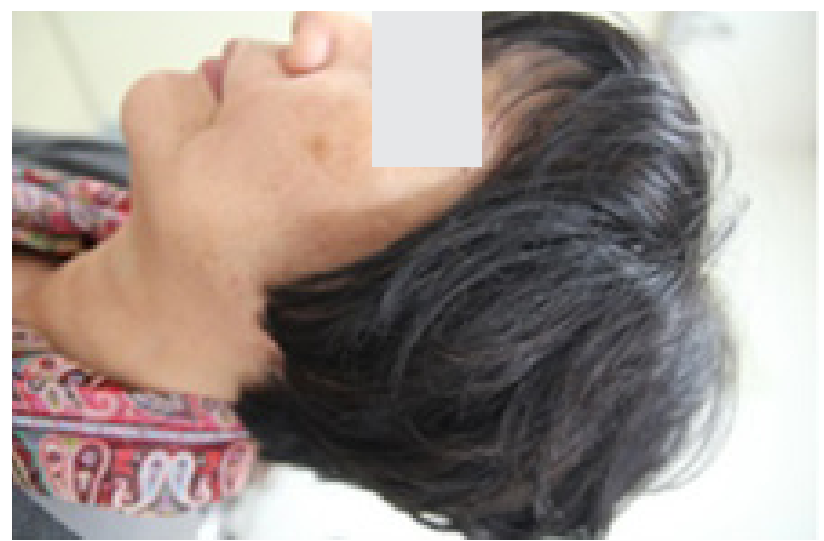

Figure 5 October 10, 2016 Appearance at the time of admission 


\section{Discussion}

The size of Heizhi (黑痣) corresponding to melanocytic nevus varies from small point sizes to fairly large sizes. Therefore, the treatment for eliminating the melanocytic nevus may also vary in size. Various acupuncture treatments for hyperpigmentation disease, including Heizhi corresponding to melanocytic nevus, include body acupuncture, intradermal acupuncture, ear acupuncture, ear acupressure, bloodletting treatment, pharmacopuncture, plum-blossom needle therapy, burning acupuncture therapy, moxibustion and guasha, etc. [9]. But most of the studies related to hyperpigmentation [10-12] and whitening [13-15] are experimental studies in Korean medicine. In addition, studies on melasma [16] and whitening [17] have been conducted on the increase of melanin pigment. There was one case of the removal of melanocytic nevi, but this was the case of removing the lentigo of small point size [18]. No studies have been performed with melanocytic nevus greater than $1 \mathrm{~cm}$ in size.

In this case, we could not apply to general acupuncture treatment with a size of $3 \times 3 \mathrm{~cm}$ or more, and we took a subcutaneous injection in several places of melanocytic nevus by mixing Hominis placenta and Soyeom reported to be effective for hyperpigmentation. Hominis placenta could play a role not only as a suppressor of melanin synthesis, but also as a regulator of antioxidant genes and might protect the skin against oxidative stress [7]. The Soyeom is composed of heat-clearing and detoxicating medicinal (淸熱解毒藥), which can inhibit inflammatory cytokine through anti-inflammatory effect and reduce pigmentation after inflammation $[8,19]$.

At the time of admission, pigmentation of layers of the melanocytic nevus was 0.6 in the epidermis, 6.3 in the dermis, and 38.6 in the complex. The HSP was applied about 20 times once a week for 5 months. At 1 year after, pigmentation of the melanocytic nevus was distributed in epidermis 2.1, dermis 21.2, complex 15.9. There was a slight decrease in pigmentation after treatment and the procedure was repeated twice. One year later, when she went back to the outpatient clinic, the melanocytic nevus had disappeared. No other treatment was received during the course.

Generalization into one case is difficult, however, it was effective only with the treatment of pharmacopuncture. The HSP procedure for a fairly large size of the melanocytic nevus seems to be effective. However, it was found that about 20 procedures and long-term observation were required.

\section{Acknowledgment}

This work was supported by basic research support project (2 years) from Pusan National University (2017.03.012019.02.28)

\section{References}

1. Siliang Xue. Adjunctive use of dermoscopy to reduce recurrence of melanocytic nevi following laser treatment: a study in an asian population. Int J Clin Exp Med. 2017;10(4):7117-22.

2. Ahn SG, Jang GH, Song JY, Cheon SH. Common skin disease. 2nd ed. Seoul: Doctor's Book. 432.

3. Han JM, Kang NR, Ko WS, Yoon HJ. The study on the Korean and western medical literatures for skin aging - wrinkle, hyperpigmentation, dry skin, facial flush. J Korean Med Ophthalmol Otolaryngol Dermatol. 2014;27(2):1-13.

4. Chang $\mathrm{CH}$, Kuo CJ, Ito T, Su YY, Jiang ST, Chiu MH, et al. CK1囚 ablation in keratinocytes induces p53-dependent, sunburn-protective skin hyperpigmentation. PNAS. 2017;114(38).

5. Lee MG, Kim KJ. Experimental studies on the whitening and anti-allergic effect of various herbal medicines that clear heat. J Korean Med Ophthalmol Otolaryngol Dermatol. 2007;20(3):71-81.

6. Kim TH, Park KY, Park JY. The effect of hominis placenta herbal acupuncture thrrapy on the postpartum women's heat feeling, sweat and thirst. The Journal of Oriental Obstetrics \& Gynecology. 2010;23(3):139-55.

7. Masahiro Y, Shinya H, Hiroshi T, Yuka K, Chihiro S, Yoko A, et al. Placental extracts induce the expression of antioxidant enzyme genes and suppress melanogenesis in B16 melamoma cells. Nat Prod Res. 2015;29(22):2103-6.

8. Song BY, Lee CH. Effect of the acupuncture or pharmacopuncture treatment for the histologic and morphologic recovery on the mouse with the burn skin. The Jourmal of Korean Acupuncture \& Moxibustion Society. 2009;26(3):81-92.

9. Kang KW, Kim EB, Kim MJ, Jang IS. Review of acupuncture and related treatment and classification of hyperpigmentation disorders in traditional medicine. The Acupuncture. 2016;33(1):69-77.

10. Kim JH, Hong SU. The effect of baickbujasan extract on the skin damage and pigmentation induced by ultraviolet irradiation. J Korean Med Ophthalmol Otolaryngol Dermatol. 2008;21(1):70-82.

11. Shin KD, Kim DS, Lee JC, Mun YJ, Woo WH, Lee YC. Effect of the ethanol extract of artemisiae capillaries herba on the hyperpigmentation induced by $\nabla-\mathrm{MSH}$. Korean J. Oriental Physiology. 2009;23(3):574-80.

12. Lee JH, In MH, Kang SH, Mun YJ, Woo WH, Lim KS. Inhibitory effect of the ethanol extract of rosae rugosae flos on the hyperpigmentaion and its action mechanism induced by \-MSH. J Korean Med Ophthalmol Otolaryngol Dermatol. 2015;28(1):41-52.

13. Lee JC, Park SY, Choi JH, Kim JH. Effect of paeoniae radix alba(PRA) on skin whitening and elasticity using melanoma cells. J Korean Med Ophthalmol Otolaryngol Dermatol. 2012;25(1):1-11.

14. Ahn JH, Kim GJ. The effect of wrinkle care and whitening by rhus verniciflua stokes. J Korean Med Ophthalmol Otolaryngol Dermatol. 2016;29(3):124-33.

15. Jeon SA, Noh HM, Jo EH, Park MC. Antibiotic, antioxidant and whitening effects of jwa kum-whan and soo 
ryeon-whan. J Korean Med Ophthalmol Otolaryngol Dermatol. 2017;30(2):100-11.

16. Kim KM, Kim MJ, Hong SU. Efficacy of hominis placenta aqua-acupuncture solution in the treatment of melasma. J Korean Med Ophthalmol Otolaryngol Dermatol. 2003;16(2):212-20.

17. Jung HJ, Do EJ, Lee JS, Park HJ, Oh GS, Kim MR, et al. A clinical research about herbal cosmetics containing momordica charntia L. extracts on the anti-wrinkle and whitening effects. J Korean Med Ophthalmol Otolaryngol Dermatol. 2011;24(2):68-78.

18. Kim HY, Park IH, Hong SH, Shin SH, Kim HR, Park SG. A case of melanocytic nevi which was treated with crucial incision acupuncture therapy. J Korean Med Ophthalmol Otolaryngol Dermatol. 2016;29(2):142-8.

19. Ruiz-Maldonado R, Orozco-Covarrubias ML. Postinflammatory hypopigmentation and hyperpigmentation. Semin Cutan Med Surg. 1997;16(1):36-43. 